Dr M J Mawdesley and Mr G Cullingford, Department of Civil Engineering, The University of Nottingham, University Park, Nottingham, NG7 2RD, England. Dr D C Morgan, Castle Rock Consultants Ltd, University Park, Nottingham, NG7 2RD, England

\title{
INTRODUCTION
}

Project planning in the form of heuristic resource scheduling might be considered to be an application of Artificial Intelligence in the sense that if simple rules are applied to the project model a reasonable plan of work usually results. The technique has been available for many years and is reviewed periodically $(1,2)$. Particular attention has been paid to comparing the heuristics and giving advice on which to use and in what circumstances the rules employed give a good plan.

Almost without exception, these techniques rely on the production of a network based model of the project which represents both the work contained within the project and the technology inherent in the chosen method of construction. Their success is often limited by the ability of the skilled planner to produce an appropriate network for the project. Experience in Great Britain indicates that many planners find it difficult to produce good networks for heuristic methods and also that they may try to use network models for totally unsuitable projects. The resulting networks suffer from problems such as

- too much detail

- not enough detail

- resource constraints built in 
Even where their use is appropriate, network models are often produced which seek to fulfil too many conflicting objectives.

In recognition of this, considerable work is being published which seeks either:

- (a) to generate new project models which recognise the limitations of networks. $(3,4,5)$

or

- (b) to use expert systems which help the planners to choose the methods which should be used. (6)

Artificial Intelligence techniques are obviously used in the second of these but do not appear in the literature on the development of project models. The authors present here a method of planning which is generally applicable to all construction and which uses artificial intelligence techniques for model building. By doing this, it is intended to assist in the area of planning in which most skill and judgement is exercised by the planner and out of which most problems arise.

\section{The Model}

The technique which is being developed is computer based and takes as initial information the general arrangement drawings and contract documents of the project together with the resource productivity information which is normally available to contractors. Although it is, at the moment, technically possible for contract drawings to be presented in digital form via CAD systems they have been digitised manually in the work discussed here.

The analysis consists of 3 phases 
Technology Formulation - which is equivalent to drawing a network. This is achieved by using predetermined rules, and an updateable knowledge base of construction sequence and temporary works requirement.

Task Recognition

- which is equivalent to selecting activities. This is achieved by recognising the packets of work which should be performed together.

Scheduling

- the production of a plan of work based on the technology and tasks formulated, the resource productivity given, and any one of a number of possible heuristics.

The paper describes the method with special reference to the areas where Artificial Intelligence is of use. Examples are given of the small projects planned by this method and the results are compared with plans produced by working engineers.

\section{Technology Formulation}

The method developed tackles the problems of model formulation in a manner which can be likened to the Finite Element Method used in Stress Analysis. The site, in plan, is divided into a grid of two dimensional elements. A rectangular grid has been chosen for simplicity in development, this leads to problems in modelling some structural forms but a degree of approximation will always be required. The fineness of the grid should theoretically be determined by the smallest plan areas in which any relevant resource could be considered to work. For example, a man might just be able to work in an area $0.5 \mathrm{~m} \times 0.5 \mathrm{~m}$ giving a grid size of $0.5 \mathrm{~m}$. In practice however, it has become apparent that this level of detail is rarely of importance and grid sizes of $5-10 \mathrm{~m}$ have been used. 
The grid square, at a particular location contains a vertical column known briefly as a pencil and the information from the drawings relating to the pencil contains data on the existing ground surface and the levels of the permanent work required at that location. The positions will usually be derived by interpolation and the recorded level will be that on the centre line of the pencil.

Within each element, the work to be done is arranged as a series of tasks which is best illustrated by means of an example. Consider the reinforced concrete retaining wall shown in Figure 1 . By examining the drawing of the finished structure, it is possible to say that the work within each element is as shown in Table la. The actual amounts of each type of work in any element are easily determined from the drawings.

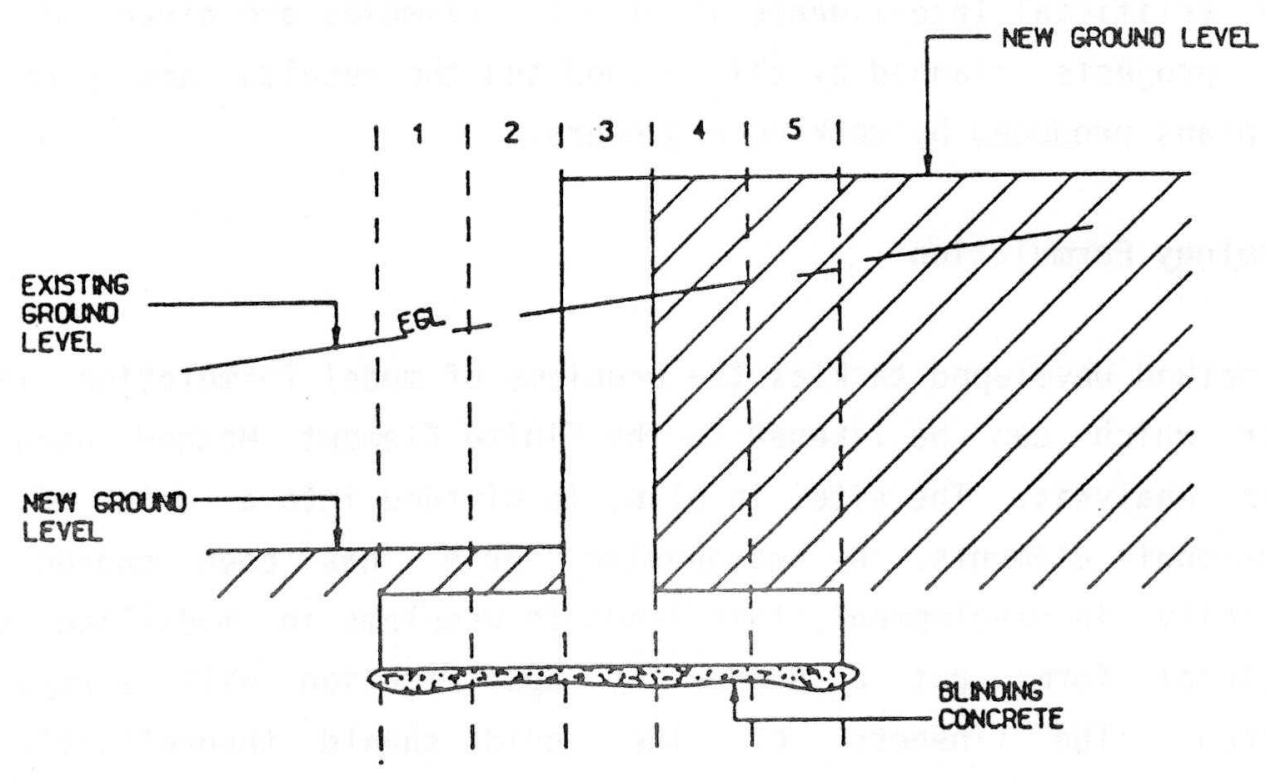

Figure 1 - An example retaining wall showing pencils 
element

1

2

3

4

5 work

backfill base, concrete base,

reinforcement, blinding

backfill base, concrete base, reinforcement, blinding

wall concrete, wall reinforcement, base concrete, base reinforcement, blinding.

backfill, base concrete, base

reinforcement, blinding

backfill, base concrete, base

reinforcement, blinding

Table 1a - Elements of work in pencil determined from final work drawing

By considering the original site state (levels), the extra work shown in Table lb can be recognised.

$\begin{array}{cc}\text { element } & \text { work } \\ 1 & \text { excavation } \\ 2 & \text { excavation } \\ 3 & \text { excavation } \\ 4 & \text { excavation } \\ 5 & \text { excavation }\end{array}$

Table 1b Extra work recognised from original level information

Further, by recognising the relative positions of the elements and by giving the system some knowledge of construction methods, it is 
possible to add the extra work shown in Table Ic.

\begin{tabular}{cl} 
element & \multicolumn{1}{c}{ work } \\
1 & base formwork, falsework for wall \\
2 & falsework for wall \\
3 & wall formwork (both sides) \\
4 & falsework for wall \\
5 & base formwork, falsework for wall
\end{tabular}

Table 1c - Extra work recognised by considering relative positions - relative positions of elements

The rules used to generate the work elements here are quite simple.

- concrete needs some formwork at its side

- formwork over a certain height requires falsework next to it for support and access.

The recognition of a full set of such construction rules would appear only to be possible if the system can ask for information in unfamiliar circumstances, recognise and retain the information given and apply it in any subsequent similar circumstances. The system is then learning and operating under a set of local and global precedents under general manual guidance. The authors have used the system only on simple projects and have not as yet enough experience to recognise 211 the problems but experience to date suggests that crude approximation at an elemental level will produce a logical progress of work through the project model and a rational overall plan.

Having recognised all the work which has to be done in any grid element, the method requires that the tasks should be placed in order. This means in effect that a network is produced for the 
element and this requires a further set of rules with which to operate. The authors use one basic rule supplemented by a set of general rules and a set of project specific rules. The basic rule is concerned with levels and reduces in its simplest form to

- only one task can be done in an element at one time. In projects such as multi storey work, this rule needs to be augmented but remains the same in concept.

This means that the network is linear (or tree structured in multi storey work). However, trying to apply the rule for say element 3 in the retaining wall example gives the network shown in Figure 2.

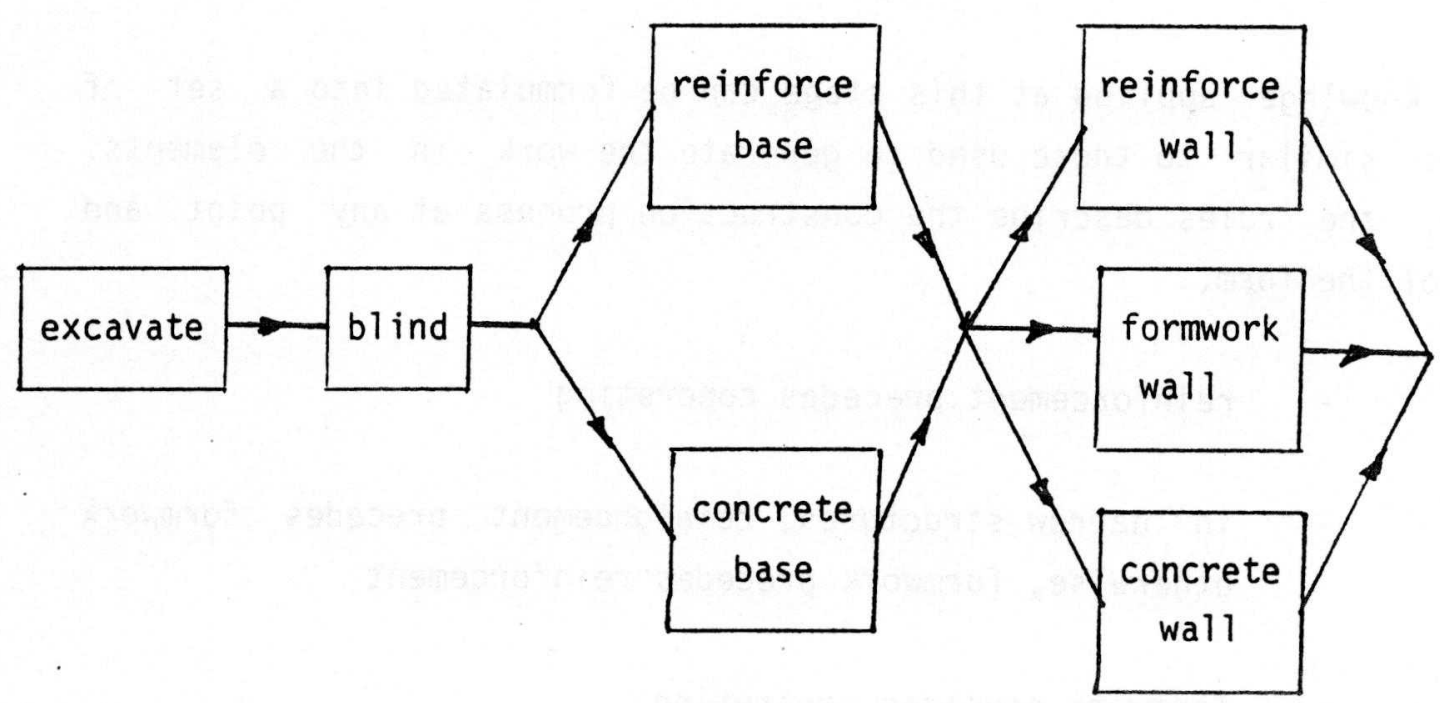

Figure 2 level based network for element 3

This is produced by working away from the existing ground level in a logical fashion. Two areas of the network are obviously infeasible showing base concrete and reinforcement and wall reinforcement, formwork and concrete able to be done together. 
Further knowledge of construction enables one to put the parallel activities into order giving the single chain network shown in Figure 3 .

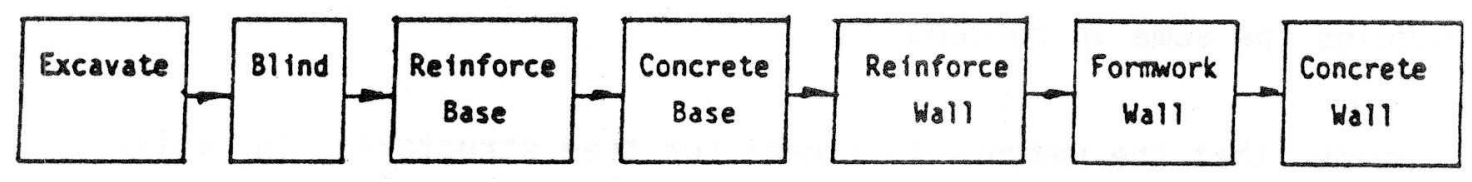

Figure 3 Network for single pencil

The knowlege applied at this stage can be formulated into a set of rules similar to those used to generate the work in the elements. Here, the rules describe the construction process at any point and are of the form,

- reinforcement precedes concreting

- in narrow structures, reinforcement precedes formwork otherwise, formwork precedes reinforcement

- formwork precedes concreting

As in the previous rule set, these rules must be built up with each new project planned although the majority of the rules will be generated in the first few projects used.

The result of the technology formulation stage is a network for each grid element. Together these networks show all the work which has to be done in order to complete the project. The logic contained within the network is necessary but not sufficient to describe the way in 
which the work should be done.

In order to determine the necessary constraints, the grouping of the work into bunches to be done together has to be considered. This is called 'task recognition'.

\section{Task Recognition}

Pencils have to be grouped for several reasons

- to satisfy the construction logic. This happens for example where one structural element such as a precast beam occupies several pencils. It is obviously desirable to ensure that the whole of a precast beam is placed together, it is perhaps less essential to pour in situ concrete in adjoining elements together. The technique has to decide which elements have to be grouped when it is able to allocate resources to more than one element at a time.

- to give the resources enough space in which to work. Any resource performing a piece of work needs a minimum area in which to work which is defined by its physical size. For example, an hydraulic excavator would have great difficulty excavating a hole only $0.5 \mathrm{~m}$ square but could excavate one rather larger. The minimum area which is required by every resource on each type of work which it can do must be given to the model. In addition to this, each resource might well require some working space around the area on which the work is actually being done. For example, in order to excavate a hole $2 \mathrm{~m} \times 2 \mathrm{~m}$ an hydraulic excavator will need some room to stand and somewhere to put the excavated material. The model must be able to determine the working area required and decide when working areas can overlap.

- to ensure that no area of work too small for the available resources is left by selecting other tasks and to ensure that access is maintained for the resources to and from the tasks. 
In order to achieve these objectives, the model must be able to look ahead beyond the current stage of work to determine the effects of a decision and to modify the decision based on the results.

The task recognition procedures built into the model to date are quite simple and need further investigation and development. They do however make the model act in a rational manner which can be recognised by engineers as being realistic.

\section{Scheduling}

The technology formulation and task recognition techniques described above have been incorporated into a scheduler to produce plans of work with a minimum of human intervention. The process followed is shown in Figure 4. It is similar in concept to many of the heuristic methods which have been used for several years but has several important differences:

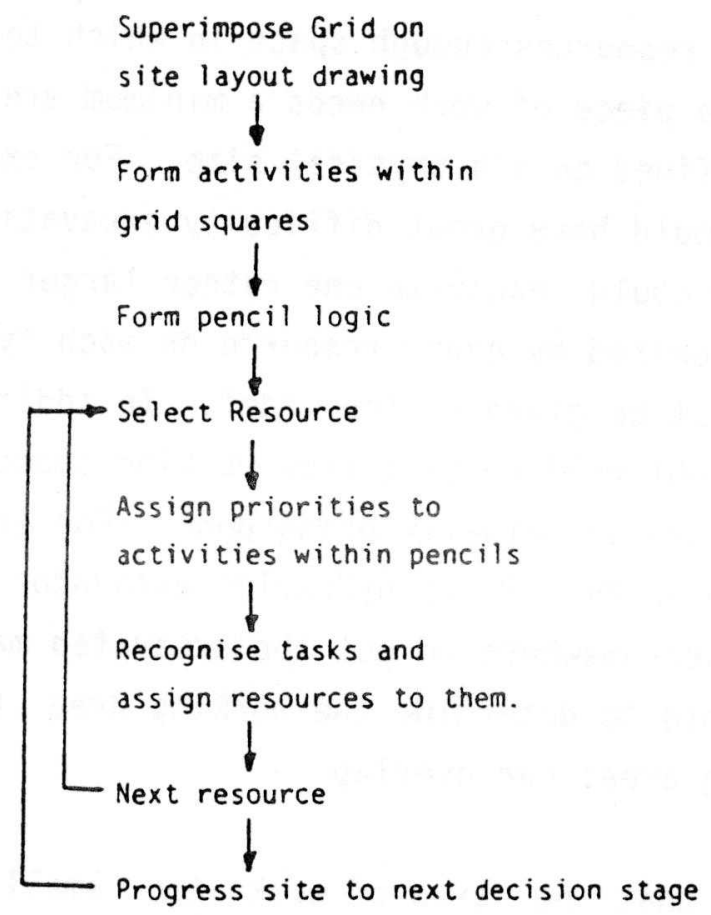

Figure 4 - Outline process of schedule 
- The resources are considered individually and assigned to tasks generated by the model. The tasks chosen depend on the factors discussed under task recognition and also on such factors as:

- the best shape of working area for the plant

- the cost of movement around site

- the interference from other working plant

- the progress on any task which can be considered to be either uniform on all the elements within the task, for such activities as concreting, or to be directional for such things as excavating a trench. In the latter case, the knowledge required by the system is greater than in the former and no experience is yet available in its implementation.

- the priorities assigned to the activities within the pencils can have any number of components. They are assigned at this stage of the schedules to allow the most recent information to be used.

Factors which have been considered so far include:

- the availability of access

- the previous position of the resource under consideration

- the structure under consideration

With these it is possible to produce apparently realistic plans but others might be considered to be useful in particular situations. 
Experience in using the system

The technique has been tested on several simple projects to determine its behaviour under different conditions and with different rules. Two examples are presented here as being typical of the scale of project presently used. The road project shown in Fig. 5 is presented as an example of a linear project for which a network would not be a particularly useful planning technique. It is relatively simple in construction sequence but the plan might change considerably depending on the positions at which access to the site was allowed. The reinforced concrete tank shown in Fig. 6 is presented by way of contrast. Its construction logic and sequence are considerably more complicated than those of the road project and the shape of the structure is not ideal for a rectangular grid.

Figures 7,8 and 9 show the plans produced for the road project by two contractors and the computer respectively. It can be seen that the two contractors proposed different methods of doing the earthworks and the rates of work of the resources considered realistic varied greatly. The computer plan was based on the rates of work used by contractor 1 and the resulting plan is similar. This plan was produced with a grid size of $10 \mathrm{~m} \times 5 \mathrm{~m}$ which results in the large blocks of work shown. Smaller grid squares result in a closer approximation to the single lines produced by contractors but do not produce a 'better' answer.

Figures 10, 11 and 12 show the plan of work for the tank project produced by the two contractors and the computer. In this project there was considerably more complexity than in the road project and this has now given rise to a greater difference between the plans produced by the contractors.

Once again, the rates of work used in producing the computer plan were those used by contractor 1 and the result shown in Fig. 12 although different to that produced by the contractor is a reasonable plan. The major differences occurred because the computer model excavated the 


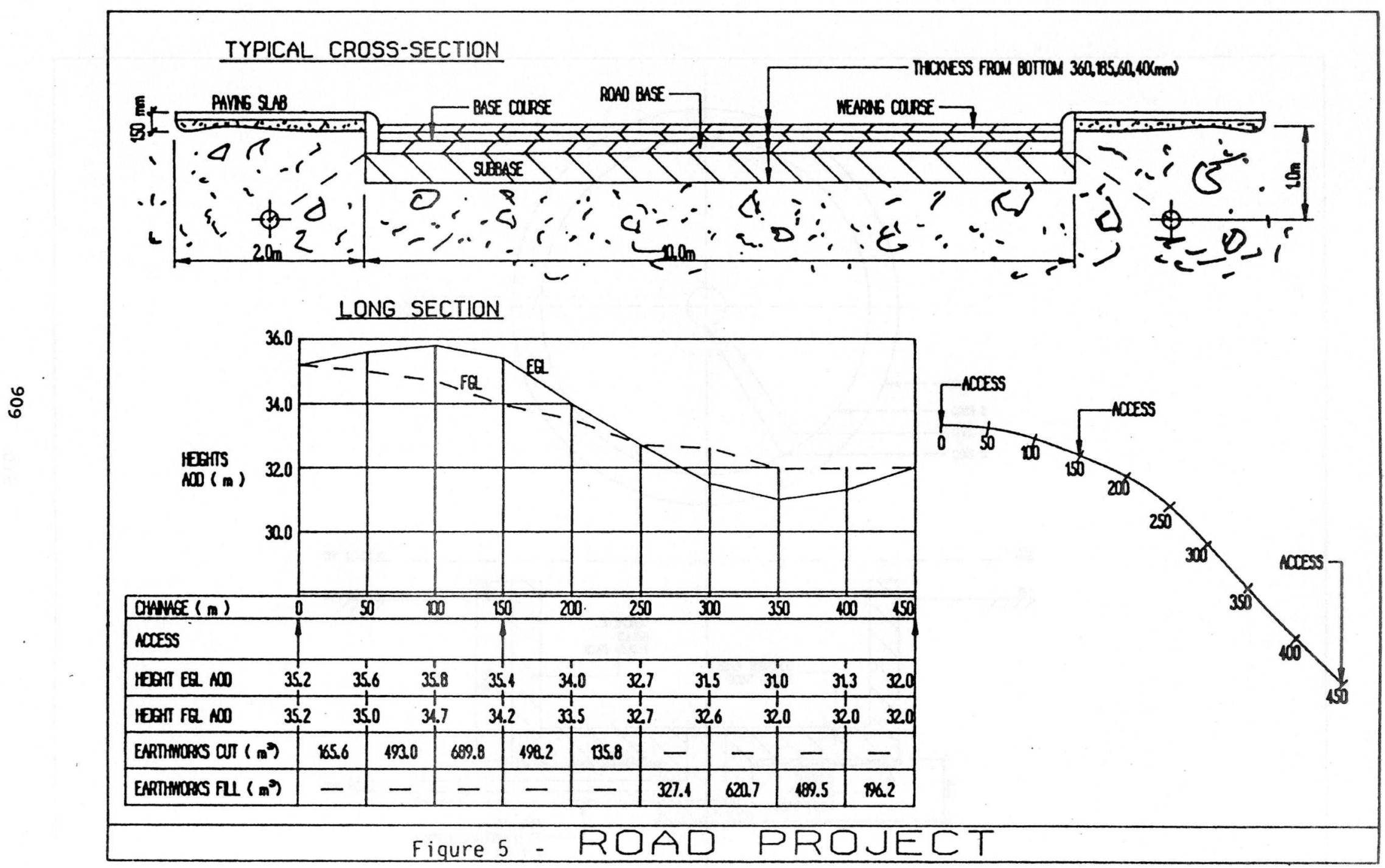




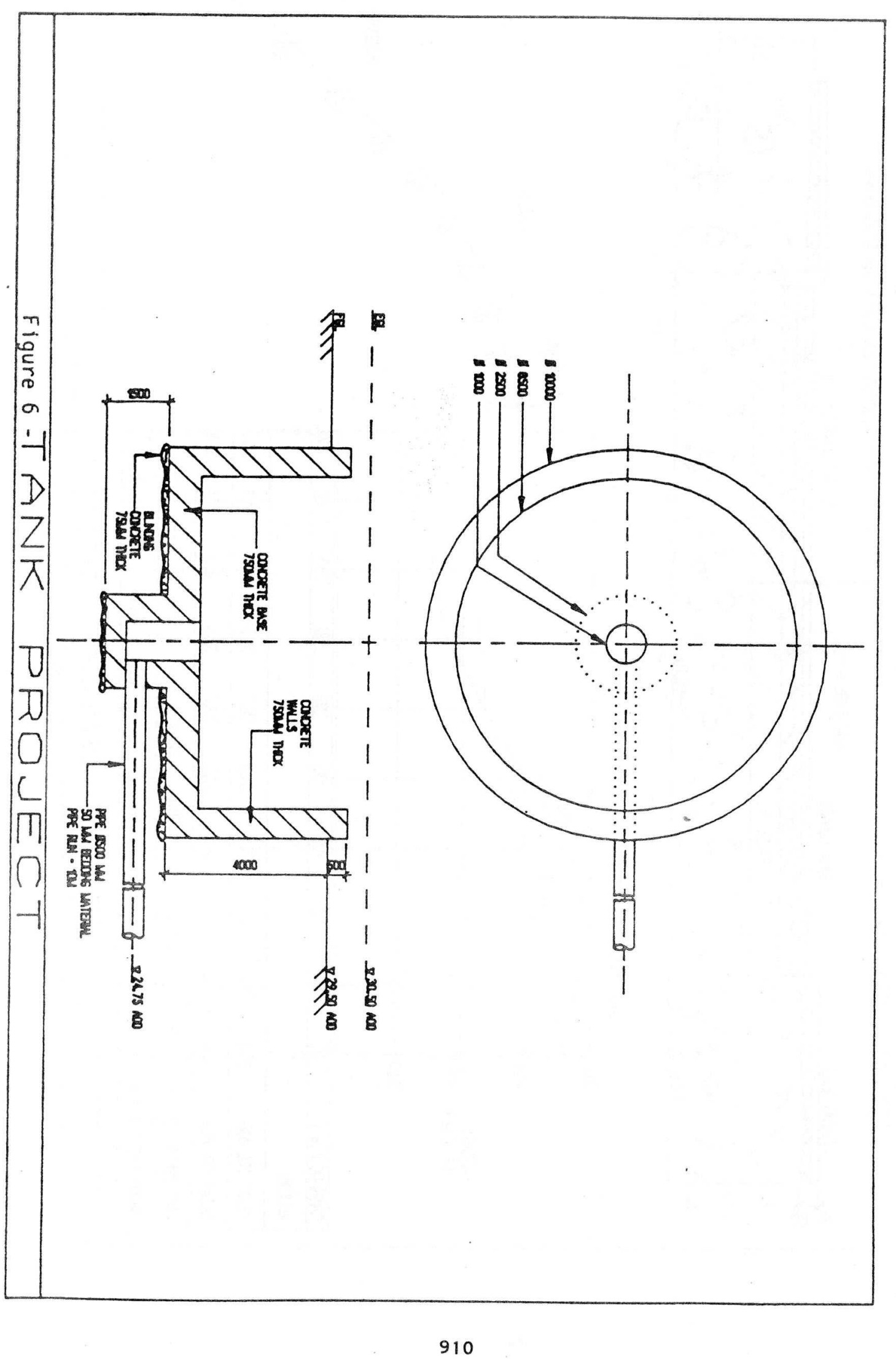




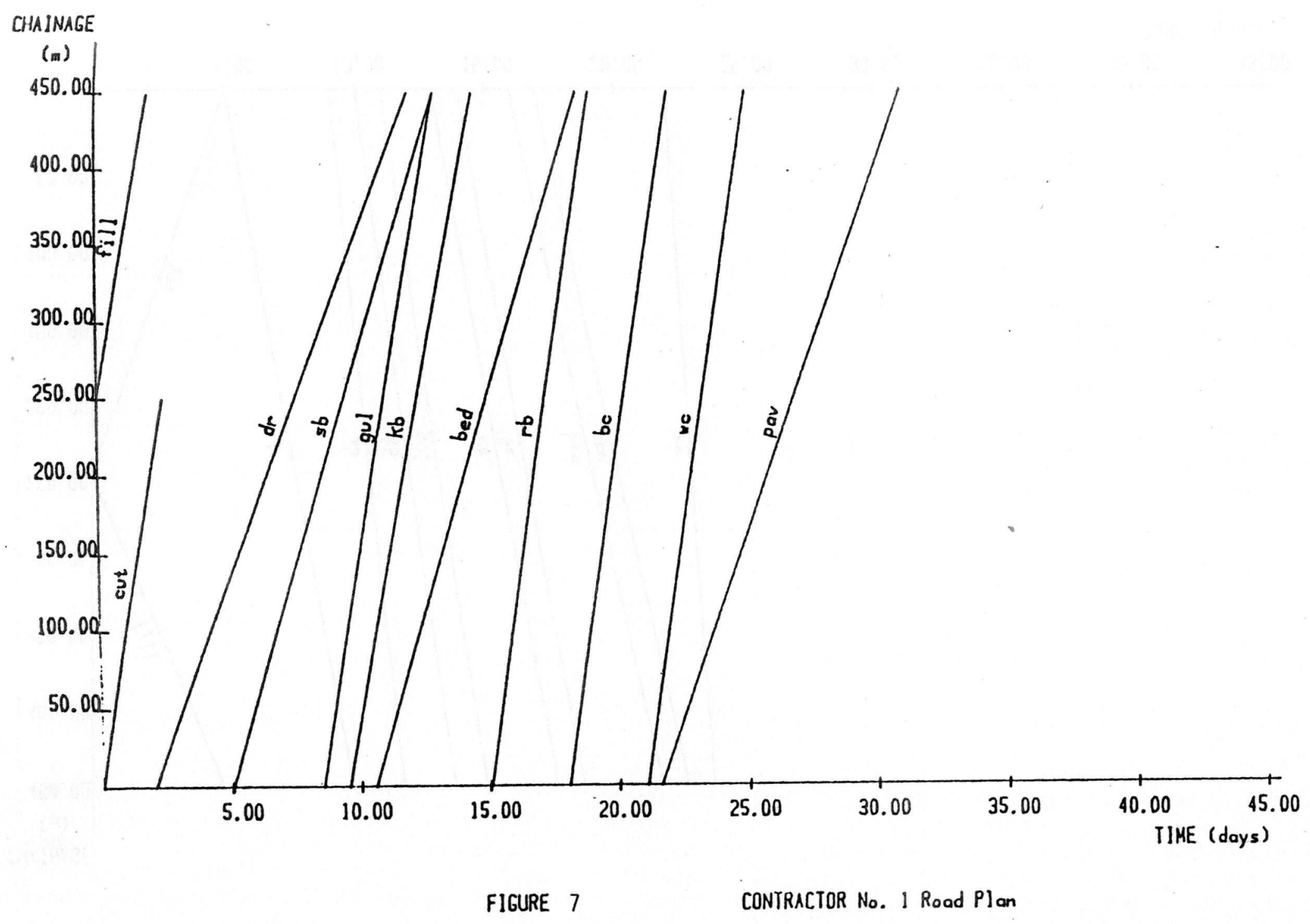

$\overline{5}$ 


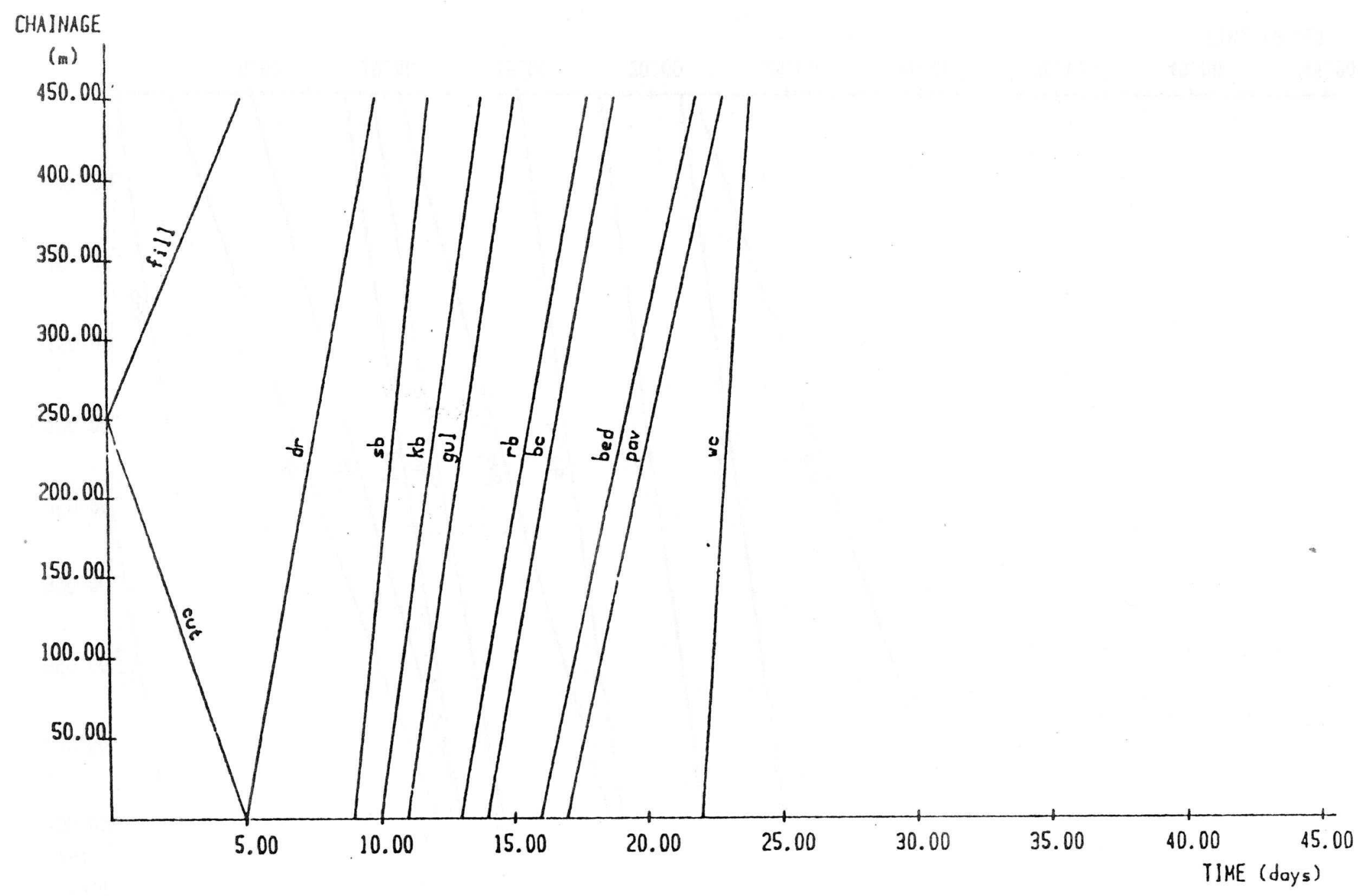




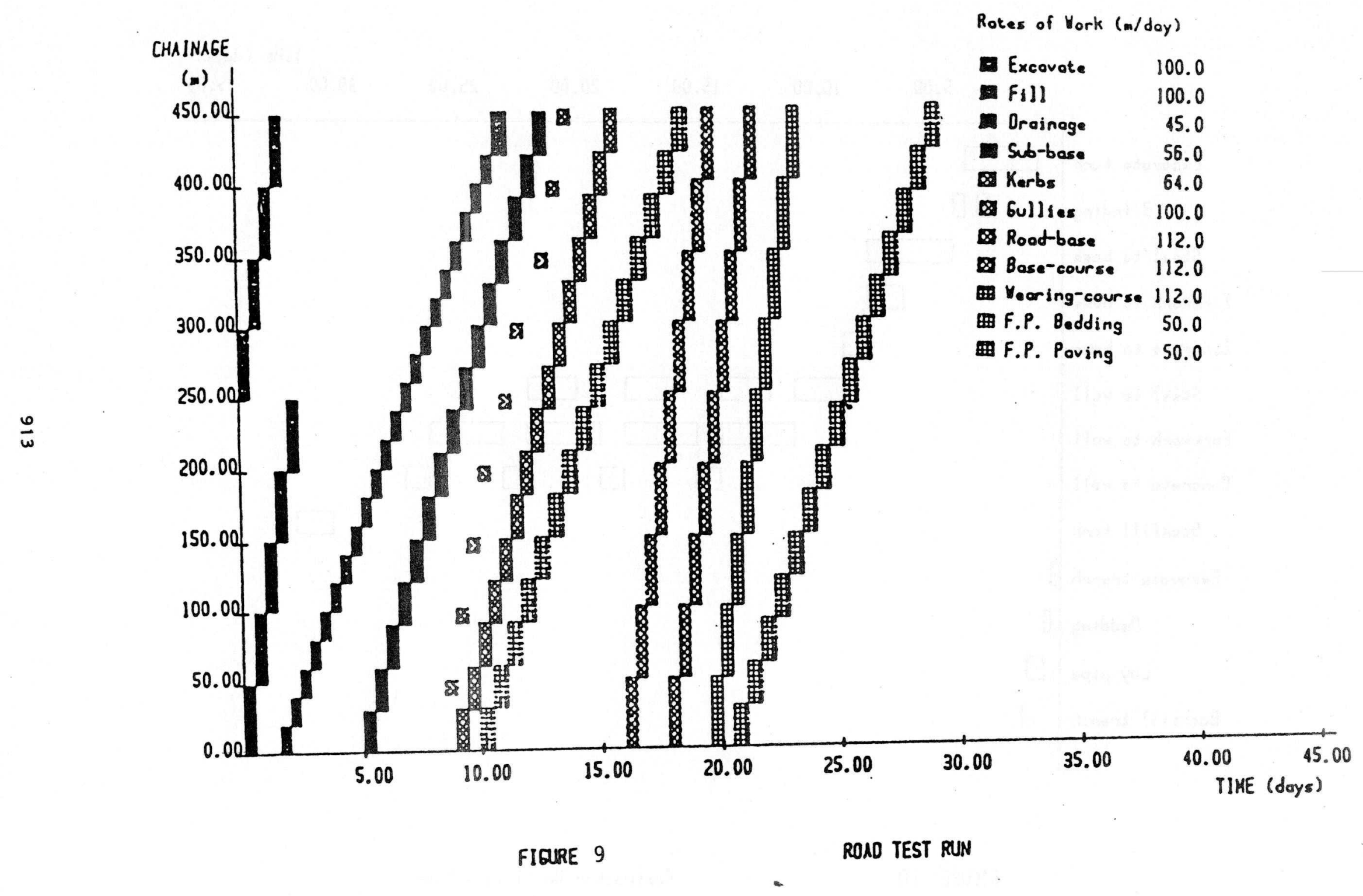




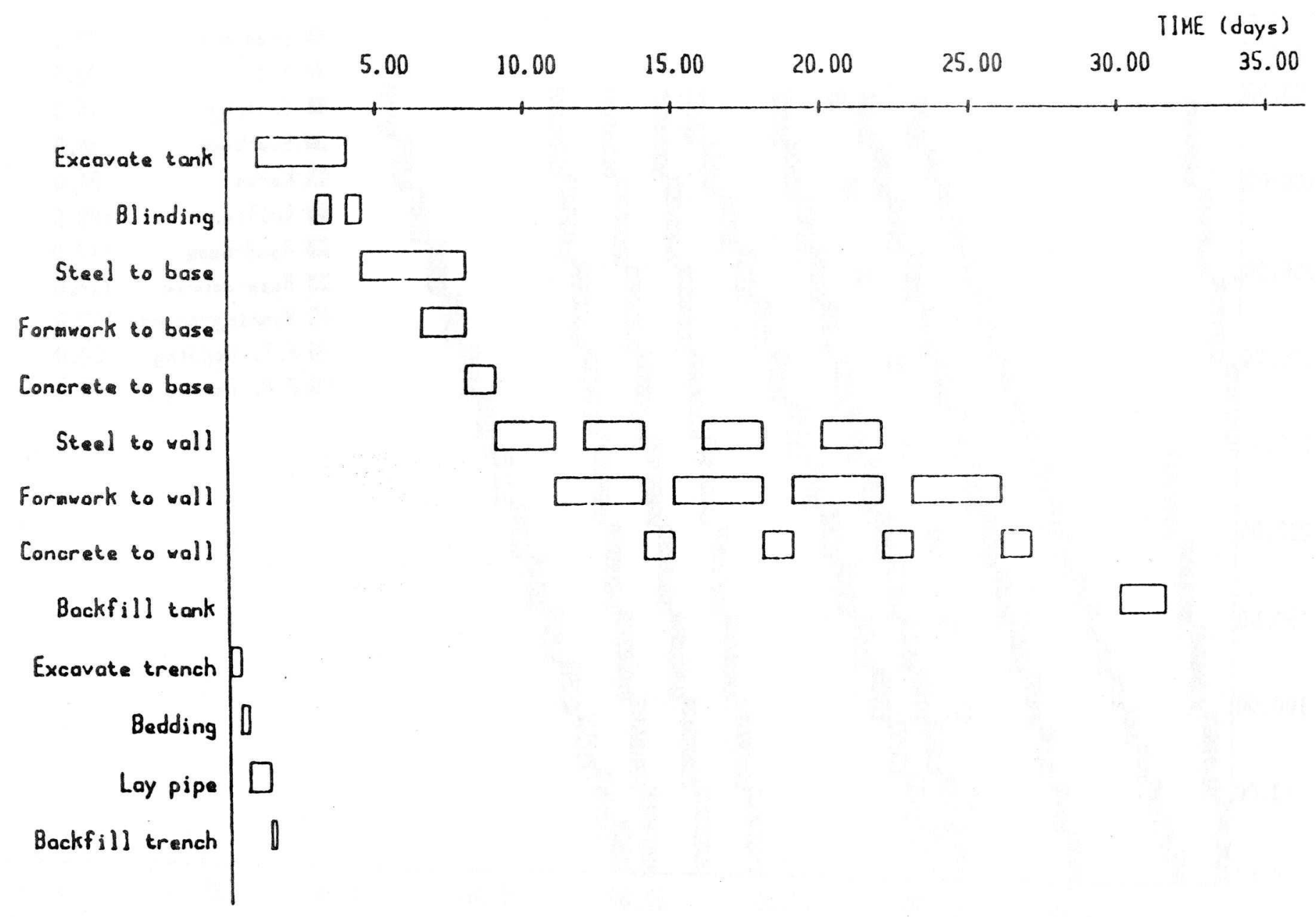




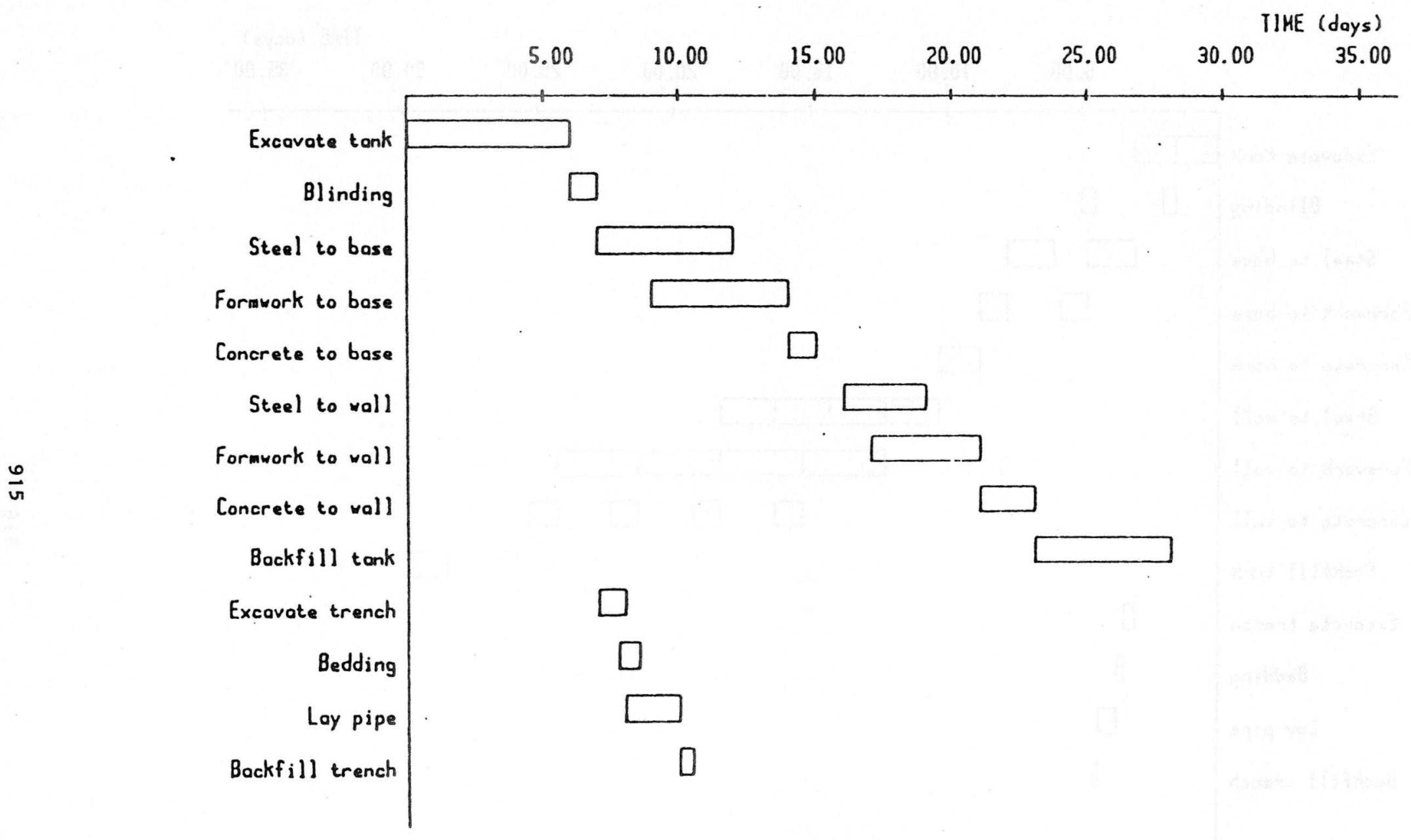




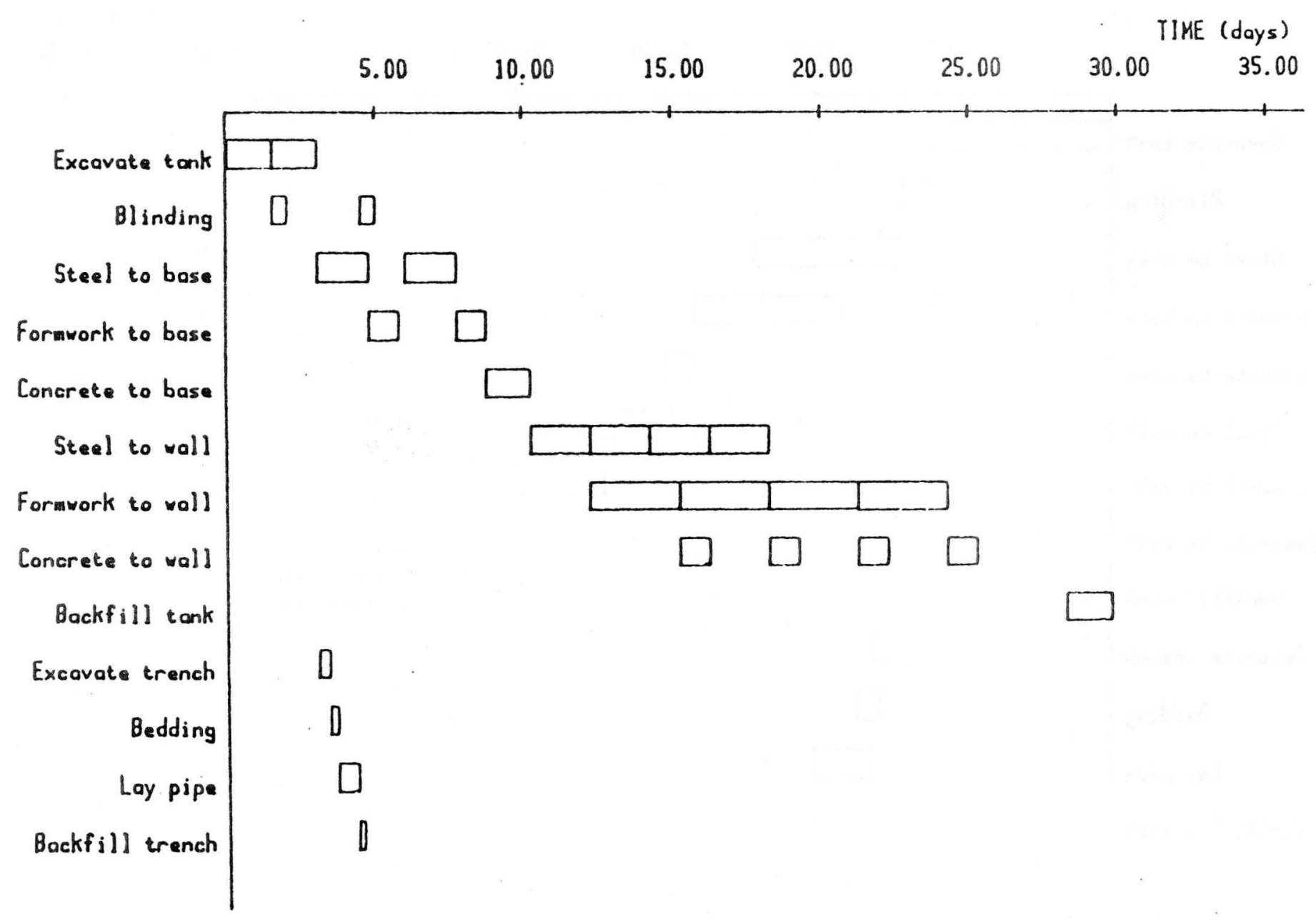


pipe trench after excavating for the tank whereas the contractor decided to excavate for the pipe first followed by the tank excavation. The authors contend that this difference is not significant. For this project a grid of $0.5 \mathrm{~m} \times 0.5 \mathrm{~m}$ was used.

The program developed is written in UCSD Pascal and runs under the $P$ system operating system. All testing and development was done on a Sage IV computer. The run time for each of the test projects to produce the schedule was in the region of 3-5 hours.

\section{Conclusion and future work}

The paper describes a method of producing a realistic plan of work for a project based on the project drawings. The resource abilities at doing work and a knowledge base of construction sequence and methods. Artificial intelligence techniques are an integral part of the method. The plans produced can be compared favourably with those produced by engineers. The computer power required by the process is large.

Future work presently in hand involves the speeding up of the process to produce reasonable computer demands and the development of the knowledge bases and rules to incorporate a larger amount of construction processes. 


\section{REFERENCES}

1 Davies E. W., "Resource Allocation in Project network models A survey", Jour. Ind. Eng. Vol. 17, No 4, April 1966 pp 177-188.

2 Elsayed E. A., "Project scheduling with resource constraint", Int. Jour. Prod. Res, 1982, Vol. 20 No 1 pp 95-103.

3 Birrel G. S., "Construction planning: beyond the critical path", Proc. ASCE (Construction Division), Sept. 1980.

4 Johnson D. W., "Linear scheduling method for Highway Construction", Proc. ASCE (Construction Division), June 1981.

5 Trimble G., "Resource Oriented Scheduling", Int. Jour. of Project Management, May 1984.

6 Wijesundera D. A. and Harris F.C., "The integration of an expert system into the construction planning process", Proc. Second Int. Conf. on Civil and Structural Engineering Computing, 1985. 